\title{
ORGANITZACIÓ I ESTRUCTURACIÓ DEL PODER AL SI D'UN ORDE MILITAR: EL CAS DE L'ORDE DE MONTESA (SEGLES XIV-XV)
}

\section{ENRIC GUINOT RODRÍGUEZ \\ Universitat de Valencia}

L'estudi dels Ordes militars en el context dels diversos regnes cristians de la Península Ibèrica té una llarga tradició que no anem a descobrir; la historia factual d'aquestes entitats, "mig monjos mig soldats" segons algun tractadista enfervorit pels seus ideals de lluita $i$ combat contra els enemics exteriors -els altres-, ha gaudit d'una llarga dedicacio en el quefer historiogràfic hispànic d'aquest segle, com pot comprovar-se en l'exhaustiva bibliografia arreplegada per C. de Ayala i altres ${ }^{1}$.

El que també pot constatar-se amb una primera aproximacio a aqueixa bibliografia és que, generalment, han dominat els treballs basats en la glossa i reproducció de les notícies tretes dels documents, on manca freqüentment una certa anàlisi més rigorosa que aporte un enquadrament historic d'aqueixes fonts.

Els Ordes militars tradicionals que actuaren als regnes hispànics medievals, tant els internacionals com ara el Temple o Sant Joan de l'Hospital, com els autoctons de Santiago, Calatrava i Alcàntara, foren creats o s'implantaren en aquests països al llarg del segle XII i, sens dubte, responent a una dinàmica social i d'organització del poder feudal que correspon a aqueix perfode del mon medieval.

\footnotetext{
'Carlos de AYALA et alii, Las Ordenes Militares en la Edad Media peninsular. Historiografia 1976-1992. I. Reinos de Castilla y León, "Medievalismo", 2 (1992), pp. 119-169; Carlos de AYALA et alii, Las Ordenes Militares en la Edad Media peninsular. Historiografia 19761992. II. Corona de Aragón, Navarra y Portugal, "Medievalismo", 3 (1993), pp. 87-144.
}

"Aprevio de Escoudios Modiovala", 25 (1995) 
Aixd fa que les interpretacions historiques i l'anàlisi del seu funcionament, trets, objectius $i$ estructures internes d'organitzacio del poder al seu si presenten uns models especifics al llarg del segle XII i fins i tot XIII, evolucionant més clarament en els segles baix-medievals vers la forma dominant de grans Estats senyorials. És en aquest context que cal situar l'especificitat del cas de l'Orde valencià de Santa Maria de Montesa, ja que la seua creació és de l'any $1317^{2}$, i el context en què es va produir va ser decisiu respecte a les formes d'organització internes, jerarquització del poder al seu si, repartiment de funcions, competències i drets entre els Mestres de l'Orde i els Comanadors, com també la seua activitat i presència quotidiana en la vida pública valenciana $i$ de la Corona catalano-aragonesa dels segles XIV i XV.

El tema de l'organització interna de l'Orde de Montesa ja va cridar l'atenció dels diversos historiadors clàssics que ha tingut l'Orde, bàsicament H.de Samper i J.Villarroya ${ }^{3}$; a partir d'ells les dades han estat copiades pels nombrosos estudis més o menys de qualitat fets en epoques més recents, bé siga sobre temes referits a l'Orde de Montesa, be siga sobre histories locals de pobles que formaren part de la seua senyoria, com ara Sueca, Montcada, Vinaros, etc. 4 .

La manera, perd, amb què foren escrites aqueixes dues obres clàssiques, sense incloure-hi una relacio acurada de les possessions territorials que tenia Montesa, sin $\delta$ sols les comandes i pobles adscrits a la Mesa Mestral en el moment en que escrivien Samper i Villarroya, va fer que totes les obres posteriors hagen reproduiit aqueixa situacio organitzativa com si fóra cosa inamovible i existent des del primer dia de l'existencia de l'Orde.

Res més lluny de la realitat ja que, com tota organitzacio, Montesa evolucionà amb el temps; els resultats d'aquest acriticisme amb les fonts

\footnotetext{
${ }^{2}$ Enric GUINOT RODRIGUEZ, La fundación de la Orden militar de Santa Maria de Montesa, "Saitabi", XXXV (1985), pp. 73-86.

${ }^{3}$ Hipólito de SAMPER, Montesa ilustrada, I, València, 1669; José de VILLARROYA, Real Maestrazgo de Montesa, I, València, 1787.

"Vid. Bartomeu RIBEUES, Examen histórico-critico de la insigne villa de Sueca, València, 1814, 3 volums; Juan José BORRAs, Histdria de Vinards, Tortosa, 1929-31; Juan José FEBRER, Petilscola, apuntes históricos, Castelló, 1924; Aurea JAVIERRE MUR, Privilegios reales de la Orden de Montesa, Madrid, s.f., Direcció General d'Arxjus i Biblioteques; Peregrín L. LLORENS RAGA, La Orden de Montesa en el Reino de Valencia durante el siglo XIV, "VIII Congreso de Historia de la Corona de Aragón", Valencia, 1967; Francisco BAllA HERRERA, Los eclesiásticos de la Orden Ecuestre de Santa Maria de Montesa, Castelló, 1983.
} 
antigues ha dut als abundants dubtes quan no greus errades quant a quins pobles conformaven la senyoria Montesiana, per no parlar de la seua distribucio interna entre els Comanadors i el Mestre. Exemples poden ser-ne les classificacions de comandes d'A. Javierre i F. Baila ${ }^{5}$. La primera autora copia Samper sense cap revisio crítica cronologica, la qual cosa li fa parlar de les comandes de Silla, Benassal, Vinaros, Alcalà o Montroi, les quals mai no existiren independents durant l'epoca medieval, o incloure directament Sueca, Montcada, Montesa i Vallada entre les possessions de la Mesa Mestral, també erroni fins el segle XVII. El treball de F. Baila encara conté més errades ja que, a més de copiar Samper, el copia malament i afirma que la Mesa Mestral estava formada per les viles que havien estat dels Ordes de l'Hospital i del Temple, o que li corresponien totes les viles situades al Maestrat de Castello, entre les quals inclou llocs que línies més avall apareixen com una comanda diferenciada; per exemple, també parla d'una Comanda de Valencia formada per Montesa, Sueca, Montcada, Massarrojos, Borbotó i Silla, la qual mai no va existir.

L'objectiu d'aquest treball és intentar esbrinar quina va ser la distribució territorial de la senyoria Montesiana quan la seua fundació i com anà evolucionant durant l'època medieval, parant també atencio fonamental al repartiment de poders $\mathrm{i}$ competencies entre els frares membres de l'Orde.

El primer fet a tenir en compte és que l'Orde de Montesa no va inventar res ni va construir la seua senyoria a partir de zero, sinб ben bé al contrari ja que, com a senyoria valenciana creada en 1317, va rebre una serie de pobles i territoris els quals tenien individualment uns trets propis; el primer problema dels montesians va ser intentar donar homogeneïtat a aquest conglomerat de viles $\mathrm{i}$ terres que procedien de l'Orde de l'Hospital, de l'Orde del Temple o fins $i$ tot del reialenc, com el terme de Montesa $i$ Vallada; a més a més, alguns d'aquests pobles havien patit una complicada historia senyorial durant el segle XIII: havien estat reialencs, senyories laiques, etc. ${ }^{6}$.

Fins i tot podrfem considerar que la majoria de les unitats territorials i de poblament que varen correspondre als Montesians tenien uns antecedents

\footnotetext{
'Aurea JAVIERre, ob.cit., pp. 65-81, i Francisco BAILA, ob.cit., pp. 38-40.

'Vid.Enric GUINOT RODRIGUEZ, Feudalismo en expansión en el norte valenciano, Castelló, 1986; Eugenio DHZ MANTECA, Notas para el estudio de los antecedentes históricos de Moniesa, "Estudis Castellonencs", 2 (1984-1985), pp. 235-305.
} 
més antics, car mantenien l'ordenació de l'espai de la darreria de l'època islàmica; aquest és el cas dels districtes castrals de Cervera, Peniscola, Xivert, Culla o Ares, tot $\mathrm{i}$ que des d'altres punts d'analisi, com ara el model dominant de relacions socials, hi va haver una neta discontinuiltat entre el món musulmà i el cristià feudal.

El fet fonamental, pero, es que durant l'estiu de 1319, arran de començar a existir en la practica l'Orde de Montesa, aquest va reunir totes les senyories i béns de l'Orde de Sant Joan de l'Hospital i de l'Orde del Temple al Regne de Valencia, llevat de la vila de Torrent i els béns Santjoanistes a la mateixa capital valenciana: unes poques terres i cases, aix 1 com l'església de Sant Joan al carrer del Trinquet de Cavallers. A més a més, Montesa va rebre aqueixes senyories organitzade's en la seua estructura anterior en Comandes, poblades amb comunitats camperoles preestablertes, majoritàriament cristianes, $i$ amb una renda feudal $i$ uns drets camperols tambe ja prefixats durant el segle anterior $i$ en ple funcionament.

Dels Templers, l'Orde de Montesa va rebre la part més considerable del seu futur patrimoni, amb les comandes, castells i batllies -tots tres noms són emprats més o menys indistintament en la documentacio de l'epoca segons de que s'estiga parlant- de Peniscola, Xivert, Polpis, Culla, Les Coves de Vinroma, Ares, tres alqueries a Borriana, Montcada i béns a Valencia, Llíria i Dénia.

Dels Hospitalers reberen els castells, entesos també com a districtes amb diverses viles, de Cervera, Vilafamés, Onda, dos alqueries a Borriana, Silla, Sueca, la Vall de Perputxent i diversos béns en cases i terres a Valencia, Ademús i Castellfabib. Finalment, del rei en Jaume II reberen la vila $i$ castell de Montesa amb l'alqueria de Vallada.

La major part d'aquests termes o senyories comprenien diversos pobles i llocs de menor entitat en el moment de la presa de possessio per part de Montesa durant la segona meitat de l'any 1319, i aqueixa organitzacio territorial no fou canviada pel nou Orde de Montesa. Aixı, per exemple, el castell de Culla incloĩa dins els seus termes la vila del mateix nom com també els pobles de Benassal, Vistabella, Atzeneta, Benafigos, la Torre d'en Besora, Vilar de Canes, Molinell, El Boi i Corbo, els quals rebien el nom de "llocs" per diferenciar la seua importància respecte a la "vila"; doncs be, els Montesians el mantingueren com una unitat orgànica en base a la Comanda. Sols a les dues ciutats en que hi havia béns procedents de Templers i Hospitalers, cas de Borriana i Valencia, va produir-se la seua inclusio en un únic organisme organitzatiu: la comanda urbana respectiva. 
Pot afirmar-se, doncs, que les comandes de l'Orde de Montesa, basades en bona part en unitats territorials d'una vila que té el nom del castell i diversos llocs més menuts en els seus termes generals, foren directament $\mathrm{i}$ total hereves $\mathrm{i}$ continuadores de les preexistents de l'Orde del Temple i de Sant Joan. Prova d'aixo és l'inventari que va manar fer fra Arnau de Soler, primer Mestre efectiu de Montesa, i amb data 25 de març de 1320 , de tots els béns que anaven a conformar el seu nou patrimoni?.

Hom hi fa una relació d'aqueixos béns, mantenint-ne la distribució en Comandes esmentada, $i$, arran la forma de funcionament $i$ gestio de les rendes senyorials fins aquell moment -per arrendaments anuals o bianuals-, Montesa va esdevenir hereu i creditor directe dels pagaments establerts i fets per Templers i Hospitalers durant l'any o anys anteriors.

Disposem aixi tant d'un grapat de noticies directes sobre aqueixos arrendaments com del seu cobrament per l'Orde de Montesa durant els anys 1319 i 1320; aquest seria el cas de l'arrendador de les rendes senyorials de Sueca, Arnau Coll, el qual el 10 de setembre del 1319 pagava al Clauer de Montesa, fra Erimà d'Eroles, 1.000 sous de la paga de setembre, o la carta que aquest mateix Clauer envia el 10 d'octubre d'aqueix any convocant els arrendadors de la batllia de Cervera, els ciutadans de Tortosa Simo Negre i Aparici Sadahu, perquè li presentaren els documents de l'Orde de Sant Joan que demostraren el seu arrendament, com també que la tercera part del preu, la "terça" de setembre, deurien abonar-se-la a ell".

És a partir d'aquestes comprovacions com podem assegurar que l'organització interna del patrimoni de l'Orde de Montesa va restar distribuït en 1320 entre les següents Comandes, que englobaven les viles i la població que en detallem:

-Batllia de Cervera: Cervera (250 cases), Sant Mateu (900 cases), Traiguera (285 cases), La Jana (65 cases), Carrascal (21 cases), Canet lo Roig (164 cases), Càlig (120 cases), Xert (124 cases), La Barcella (25 cases), el Molinar (10 cases), Rossell (50 cases) i el Mas dels Estellesos (15 cases); total sumen 2029 cases, un poc més de 8.000 persones, tots cristians. Adscrita al Mestre.

\footnotetext{
'Arxiu Històric Nacional, Madrid (endavant AHN), Ordes Militars (endavant OOMM), Montesa, Llibre 87 lc, i també Consell Ordes, Lligall 2174.

'Arxiu del Regne, València (endavant ARV), Clergat, Montesa, lligall 895, caixa 2357, Llibre registre, s.f.
} 
-Comanda de Peniscola: Peniscola (250 cases), Benicarlo (33 cases) i Vinaros (90 cases); total 373 cases, uns 1500 habitants, tots cristians.

-Comanda de Xivert: Xivert (75 cases, moros), Alcala de Xivert (200 cases), Polpis ( 30 cases), Castellnou (18 cases) i Alcossebre (6 cases); són 329 cases, unes 1300-1400 persones; d'elles 75 cases de sarraïns, un $23 \%$.

-Comanda d'Ares: la vila d'Ares (250 cases); uns 1000 habitants, tots cristians.

-Comanda de Culla: Culla ( 80 cases), Benassal (400 cases), Molinell (25 cases de moros), Corbo (despoblat), El Boi (20 cases), Vistabella (300 cases), Benafigos ( 30 cases), Atzeneta (180 cases), la Torre d'en Besora (25 cases) i Vilar de Canes ( 20 cases); en total sumen unes 1080 cases, amb sols 25 de moros, i uns $\mathbf{4 3 0 0}$ habitants.

-Comanda de Les Coves: Les Coves (250 cases), Albocasser (300 cases), Salzadella (190 cases), Vilanova d'Alcolea (90 cases), Tírig (50 cases), La Serra (Serratella, 20 cases) i La Torre del Domenge (no consta la poblacio); total, unes 900 cases i 3.600 persones, tots cristians.

-Comanda de Vilafamés: Vilafamés (170 cases) i la Vall d'Alba (20 cases); total, 190 cases i uns 760 habitants, tots cristians.

-Comanda d'Onda: Onda, amb 600 cases de cristians, i la moreria d'Onda i alqueries de Tales i Artesa, tots tres de moros (180 cases); total, 780 cases, un $23 \%$ d'elles de moros, i unes 3210 persones.

-Comanda de Borriana: formada per cases $i$ terres a la ciutat, $i$ quatre alqueries de cristians: Vinaragell (25 cases), Beniham (8 cases), Seca (6 cases) i la Pobla (6 cases); sumen 45 cases i unes 180 persones.

-Batllia de Montcada: Montcada (80 cases) i alqueries de Massarrotjos, Borboto, Carpesa i Binata (70 cases més); sumen unes 150 cases $i$ uns 600 habitants, tots cristians.

-Comanda de Silla: Silla, amb 200 cases (800 habitants), tots cristians. cristians.

-Comanda de Sueca: Sueca, amb 400 cases (1600 habitants), tots

-Vila de Montroi: Montroi, amb 30 cases de moros i 1 de cristians (unes 125 persones); adscrita al Clauer a partir de 1339.

-Vila de Montesa: Montesa i alqueria de Vallada ( 200 cases en total, $i$ unes 800 persones, totes cristianes). 
-Comanda de la Vall de Perputxent: Perputxent, l'Orxa, Benillup, Alquinència, Benitàric i Beniarrés (60 cases de moros i 30 de cristians, amb unes 360 persones).

-Comanda de la ciutat de Valencia: cases bàsicament al barri de la Xerea, envoltant l'antic palau del Temple, i terres a la rodalia de la ciutat.

-A més a més, l'Orde de Montesa va recollir terres i cases a Dénia, Llíria, Morella, Ademús i Castellfabib en nombre reduït.

En total sumen 64 pobles, dels quals sols 11 són aljames sarraïnes i, a més, prou menudes en general; una població total d'unes 28.000 persones com a minim en 1320 , de les quals unes 1500 serien musulmans, sobre un $5 \%$ del total.

A partir d'aquestes dates alguns pobles o alqueries acabaren despoblats, com Alcossebre o Castellnou; d'altres cresqueren i acabaren fent-se municipis en epoques més tardanes, cas del Mas dels Estellesos -actual Sant Jordi del Maestrat-; però les agrupacions bàsiques de castells i batllies es mantingueren com a tals durant els segles medievals. Fou a partir d'aquestes que l'Orde de Montesa institucionalitzà les seues Comandes, normalment limitant-se a mantenir el nom i els trets de les existents en temps de Templers i Hospitalers, cas de Culla, Les Coves, Peniscola, Xivert, Vilafamés, etc.; sols en certs casos va agrupar alguns d'aqueixos pobles/unitats senyorials en una mateixa Comanda de nova creació, cas de Sueca i Silla, amb la idea de millorar les rendes corresponents al seu comanador, com el Clauer de l'Orde; de tota manera ambdós pobles mantingueren la seua autonomia i particularitats propies quant a la situacio $i$ als drets dels seus veïns camperols, tant individuals com col.lectius; finalment, hi haurà el cas de termes com el de Cervera, que deixarà de ser una comanda, o el de la vila de Montesa, que mai no serà constituïda com a tal, en raó de la seua adscripció economica al manteniment de la Mesa Mestral de Montesa.

Aquestes caracteristiques són les que ens fan parlar d'una diferent organització segons el nivell de que tractem: un de primer és la xarxa de castells i viles en que es troben organitzades les diverses comunitats camperoles, la qual va restar invariable llevat dels propis daltabaixos de la seua demografia; hi hagué, pero, un segon nivell organitzatiu basat en les Comandes i la Mesa Mestral, el qual va ser força més fluctuant i variable car en bona mesura ve a palesar la concrecio del repartiment d'excedent, de la renda feudal apropiada pels feudals, entre els diversos membres que componien l'Orde de Montesa. 
Tal com hem afirmat, la primera xarxa, la dels nuclis de poblament que conformaven el patrimoni de Montesa durant l'epoca baix-medieval, va restar practicament inalterable en aqueixos dos segles, $\mathrm{i}$ fins i tot fins la Desamortització del segle XIX; la contracció demografica farà desaparèixer durant el segle XV els llocs de la Barcella, el Molinar, Polpis, Castellnou, Alcossebre, Corbo, El Boi i Molinell, amb la concentració dels veïns en les viles properes més grans, pero sols va donar-se una alteració política en el patrimoni senyorial de Montesa: es tracta de la intermitent eixida $i$ entrada de la vila de Peníscola a partir de la seua apropiació per Benet XIII, el Papa Luna, el 10 de juliol de 1410, quan la separà de Vinaros i Benicarlo; va restar com a territori Pontifici durant la resta de la seua vida i continua en mans dels seus cardenals fins al reconeixement de Clement VIIIe com a únic Papa; aquest va lliurar Peníscola al rei Alfons el Magnànim el 16 de desembre de 1429, i es mantingué com a vila de reialenc fins al març de 1441, quan el mateix monarca la vengué amb carta de gràcia per 150.000 sous a l'Orde de Montesa, la qual va reunificar-la amb Vinaros i Benicarlo, pero no com comanda sino adscrites a la Mesa Mestral.

Finalment, en juliol de 1488, el rei Ferran el Catolic va aconseguir un préstec garantit per les principals viles reials valencianes $i$, retornant els 150.000 sous a Montesa, reintegrà de forma definitiva Peníscola al Patrimoni Reial; aixI d'ara endavant varen restar Vinards i Benicarlo com una nova comanda de Montesa, tal com les identifica H. de Samper en la seua obra del segle XVII.

Un altre tema diferent és el de com varen ser distribuïdes aqueixes viles $i$ termes entre els diversos frares membres de l'Orde militar i com va organitzar-se internament aquest per al control i aprofitament de la seua senyoria.

Els historiadors classics de Montesa, els susdits Samper i Villarroya, aporten un esquema de funcionament intern, de repartiment de les competencies i del poder, que respon al model que ells conegueren i que existia en el seu temps respectiu, especialment en el cas de H. de Samper de meitat del segle XVII, car Villarroya el segueix en bona mesura i aixI ho han fet la majoria d'estudiosos posteriors que han escrit sobre Montesa.

La piràmide jeràrquica que retrata Samper é, com hem dit, la de la seua epoca Moderna, i ve a ser la següent: un Mestre com a cap suprem, un Comanador Major que el ve a substituir en els casos necessaris, un Clauer que controla les rendes generals, un Sots-comanador del Convent que governa el convent religiós de la vila de Montesa, un Sots-clauer que pot 
substituir el Clauer en el seu moment, un grapat fluctuant de Comanadors, pero que solen ser set, uns companyons que són frares que no han accedit encara a una comanda perque son poques $i$ esperen una vacant, $i$, finalment, amb una altra gradació jeràrquica, els membres eclesiàstics de l'Orde, Priors de diverses comandes, $i$ els religiosos que fan vida conventual a l'edifici del castell de Montesa.

Allo important és que, revisant la documentació medieval de Montesa, aquesta organització interna no sembla existir ni d'una forma estable ni tampoc des dels moments de la fundacio de l'Orde en 1319. Quan el delegat papal nomenava fra Guillem d'Erill primer Mestre de Montesa en juliol d'aqueix any, al palau reial de Barcelona $i$ en presència del mateix monarca Jaume II, el nou Mestre procedi a rebre els primers frares montesians i podem comprovar com sols existien ambdues categories: Mestre d'una banda, i frares de l'altra, sense que puguem constatar si foren extrapolats els diversos títols $i$ carrecs de que havien gaudit fins aqueix moment els frares del Temple i de Sant Joan fins poc abans en el context del Pais Valencià. Aixo és, que el Comanador de Cervera de l'Orde de l'Hospital, a tall d'exemple, no fou substituiit per un nou comanador de Montesa que ocupés immediatament el seu càrrec sino que els documents només ens parlen dels diversos frares d' "a peu", sense títols de Comanador inicialment.

L'única excepció fou el ràpid nomenament d'un Clauer, fra Erimà d'Eroles, potser per rab de la vellesa i malalties del primer Mestre, fra Guillem d'Erill, la qual cosa li impedi prendre possessió personal de les seues noves senyories $i$ encarregà tal feina al susdit Clauer?.

D'altra banda, el nou Orde de Montesa no va ser cap organisme revolucionari $i$, com a hereu del patrimoni Templer i Hospitaler, també va ser hereu de les formes organitzatives d'aquests Ordes militars, a més a més incardinades en les regles generals dels Ordes de Calatrava i del Císter, a les quals remetia directament la butlla de fundació del Papa Joan XXII ${ }^{10}$.

És aixf, doncs, com Montesa va anar configurant-se a nivell intern en aquesta primera epoca de la seua existencia, amb unes pautes marcades per la susdita butlla de fundacio, que declarava tant la lliure eleccio de Mestre per part dels Capitols de l'Orde, com el dret Mestral de rebre nous frares i nomenar-los per als possibles càrrecs interns; butlles posteriors

'ARV, Clengat, Montesa, lligall 895, caixa 2357, llibre registre s.f.

${ }^{10}$ Text publicat per Jose VIUARROYA, ob.cit., 2, pp. 1-11. 
anaren a poc a poc completant aquesta legislacio $i$ tot sembla indicar que en general anaren en direcció a consolidar les superiors competencies dels Mestres en front del Capitol.

Un exemple d'aquesta diferent jerarquia pot ser el jurament que va fer el segon Mestre, fra Arnau de Soler, el 19 de maig del 1320 de no alienar els béns de l'Orde sense permís Papal, prova evident en la nostra opinio de que era ell qui tenia aqueix poder i no els altres frares de l'Orde o el Capitol ${ }^{11}$.

El mateix sentit pot deduir-se de la Butlla del dit Papa Joan XXII, de 23 de juliol del 1326, quan, a petició del Mestre de Montesa, revocà en part el jurament esmentat $i$ li donà permis, amb consulta $i$ aprovació dels frares, per donar a cens i establir tots els béns, cases i terres pertanyents al patrimoni de l'Orde, deixant ben clar, pero, que aqueixa competencia era propia del Mestre en persona ${ }^{12}$.

Aquesta butlla vingué a ratificar el que sembla la realitat del comportament $i$ jerarquitzacio interna de Montesa car, en un dels primers Capitols celebrat el 23 de març de 1320, tots els frares atorgaren poders al seu Mestre, fra Arnau de Soler, per a establir cases i terres, nomenar carrecs, confirmar privilegis, etc., en nom de l'Orde ${ }^{13}$. No és d'estranyar aquesta situacio car podem trobar un repartiment de competencies i la preeminencia dels Mestres practicament en tots els Ordes militars peninsulars.

D'altra banda, aqueixes competencies són molt semblants a les que assenyala H. de Samper com a vigents al segle XVII: els Mestres tenien tot el poder economic, el governatiu i l'exercici de la jurisdiccio, la capacitat de nomenar tots els carrecs, dignitats i beneficis interns, com ara Comanadors, Priors, etc., com també el llevar-los-els si ho consideraven adient. En bona mesura és aixo el que veiem exercit pel mestre fra Arnau de Soler en els primers anys: establiments de terres, de monopolis senyorials, concessio de franqueses als pobles $i$ vassalls de la seua senyoria, cobrament de les rendes respectives, exercici de la jurisdicció $\mathrm{i}$ atorgament de càrrecs de delegació

\footnotetext{
$11 \mathrm{n}$...possessiones vero ad mensam mei monasterii pertinentes, non vendam nee donabo neque impignorabo neque de novo infeudabo vel aliquo modo alienabo inconsulto Romano Pontifice..." editat per José VILLARROYA, ob.cit., 2, pp. 30-31. 220.

${ }^{12}$ AHN, OOMM, Montesa, llibre 733c, fols. 94-99; publica José VILLARROYA, 2, pp. 217.

${ }^{13} \mathrm{AHN}$, OOMM, Montesa, Llibre 733c, fol. 62-65, i ARV, Clergat, Montesa, Lligall 867, caixs 2279-80.
} 
senyorial, com ara batlles, notaris, etc. arreu de la seua senyoria, com tambe els interns de l'Orde: Comanador, Clauer o Lloctinent de Montesa ${ }^{14}$.

El protagonisme del Mestre de Montesa ja des d'aquests primers anys, arrendant els drets senyorials de terres i pobles sencers, nomenant funcionaris i repartint dignitats, fa que no coincidim amb l'opinio de $\mathrm{L}$. Garcia-Guijarro ${ }^{15}$, el qual parla del no-repartiment dels béns Montesians durant els primers anys, la qual cosa és certa; pero creu aquest autor que eren controlats conjuntament pels principals dignataris, ja que el nombrs reduït de cavallers frares no feia necessària una gran subdivisió de les funcions. Més bé la documentació d'aquests primers anys de l'existència de Montesa palesa, a més d'aqueix protagonisme del Mestre que hem assenyalat, els primers passos vers una descentralitzacio de funcions, un repartiment d'arees de competencia, ates que el Mestre no podia arribar a tot; aquest procés és el que culminaria amb el Capitol general de l'Orde de l'any 1330, quan va fer-se el repartiment d'ingressos economics entre totes $\mathrm{i}$ cadascuna de les categories dels frares Montesians, assignant el cobrament de rendes a l'ocupació i la gestió dels càrrecs corresponents.

Detallant un poc més, pensem que podrien distingir-se una sèrie d'etapes en aqueixa recerca de millors formes de gestió senyorial i que, sens dubte, la primera de totes foren els mesos inicials quan fra Guillem d'Erill, el primer Mestre, delicat de salut, va nomenar fra Erimà d'Eroles com a Clauer de Montesa el mateix dia de la fundació de l'Orde, el 22 de juliol de 1319. Pocs dies després, durant l'agost, aquest frare va viatjar per bona part de les viles valencianes que conformaven la nova senyoria $i$ rebe els homenatges feudals de vassallatge dels seus veïns, en nom del susdit Mestre, a més de cobrar les rendes que pertocaven; per exemple, el 10 de setembre cobrava la paga de l'arrendament anual de la vila de Sueca, de mans del seu arrendador ${ }^{16}$.

Tot i aixo, la figura del Clauer fent les funcions del Mestre podem considerar-la excepcional, donada la malaltia i ràpida defuncio d'aquest. És per aixo que, arran del nomenament Papal del segon Mestre de Montesa, fra Arnau de Soler, el febrer de 1320, el Clauer, tal com ho conta Samper i ho

\footnotetext{
14ARV, Clergat, Montesa, lligall 895, caixa 2357, Llibre registre del mestre fra Amau de Soler, 1320-1325, s.f.

is Luis GARChA-GUUARRo, Dasos para el estudio de la renea feudal Maestral de la Orden de Montesa en el siglo XV, Valencia, 1978.
}

${ }^{16} \mathrm{ARV}$, Clengat, Montean, lligall 895, caixa 2357, Llibre registre, s.f. 
constatem a la documentacio, tingué com a primera missio el control economic $\mathrm{i}$ forniment d'aliments $\mathrm{i}$ objectes necessaris al nou Convent de frares clergues fundat a la vila de Montesa, tot i que no constatem que tinguera rendes concretes assignades per a complir aquesta funcio:

...el cuydado de distribuir el mantenimiento neceseario a las pereonas que residian en el Sacro Convento. Asai $x$ ha eatylado en Calatrava, y en la Visita primera que tuvo nuestra Orden en el año 1326 \& dispuso lo siguiente: Item, mandamos al Clavero que proves el Convento de las cosas necesarias y, siempre que acontezca que el Convento no tenga pan, vino o came, pescado, queso o azeyte para las cozinas o para las lámparas, y cera para la iglesia, por cantos días como faltare eaté el Clavero en convento en pan y agua... ${ }^{17}$.

Tot fa pensar que aquestes funcions són molt més concretes i materials que les de caràcter jeràrquic i honorffic que tindria amb el temps, com a tercer grau dins l'Orde de Montesa, al darrere del Mestre i del Comanador Major.

A partir de febrer de 1320 fra Arnau de Soler assuml el càrrec de Mestre i podem parlar de l'inici d'una segona etapa on hom constata una tendencia vers el repartiment de competencies $i$ establiment d'una jerarquia interna. Aqueix mateix dia nomena fra Berenguer de Montoliu Comanador major de l'Orde, sens dubte amb l'objecte de resoldre el problema que acabaven de patir amb la malaltia i mort del primer Mestre, que els va deixar sense cap reconegut durant el perfode de transició fins a la nova eleccio del seu successor, segons ho establia la butlla fundacional. És per tot aixo que la figura del Comanador Major degue ser pensada per omplir aqueix buit $i$ substituir el Mestre difunt durant el perfode electoral, a més de, usualment, quan aquest s'absentara dels seus estats patrimonials i/o del regne valencià'.

Aquesta segona etapa, que durà aproximadament els anys $1320 \mathrm{i}$ 1321, els primers d'existencia de Montesa, es caracteritzà pel nomenament d'uns pocs frares com a lloctinents del Mestre en diverses viles de la senyoria, a més d'altres laics amb funció d'administradors dels béns i rendes de l'Orde, pero no apareix encara la figura del Comanador.

\footnotetext{
${ }^{17}$ Hipolit de SAMPER, ob.cit., 2, p. 420.

${ }^{18}$ Hipolit de SAMPER, ob.cit., 2, p. 412.
} 
El primer lloctinent que hem documentat és fra Berenguer de Montoliu, que havia estat fet Comanador Major poc abans, com hem dit, i que el 24 d'abril de 1320 fou nomenat pel Mestre Lloctinent i procurador als castells de Montesa, Perputxent, Sueca, Silla i cases de Valencia amb amplies competencies administratives i econdmiques sobre els pobles respectius $^{19}$.

Com podem constata, es tracta d'una clara divisió de competencies de govern al si de l'Orde en funció de la distribució geogràfica de la seua senyoria: acr el Mestre delega el seu poder sobre totes les viles situades al centre i sud del Pars Valencià; només falten en el Ilistat els casos de Montroi -sols incorporat a Montesa en 1339-, i la batllia de Montcada, donada en benefici al noble Vidal de Vilanova per la seua vida en rao dels seus treballs al servei de Jaume II per aconseguir la fundació de l'Orde per part del Papat.

Dos mesos després, en juny de 1320, va donar-se un nou nivell de delegacio de poders: el Comanador major, fra Berenguer de Montoliu, el qual havia estat poc abans fet lloctinent i procurador del Mestre a les viles del centre i sud valencià, va demanar i obtenir del Mestre el nomenament de fra Guillem Cerdà com a lloctinent del comanador Major a la vila de Sueca, la més rica i poblada de les que tenia aquest sota el seu govern; el text indica clarament que no es tracta del nomenament d'un Comanador autonom ni tampoc de l'assignació de les seues rendes feudals per a una destinacio concreta sin 6 d'una delegacio de poders ${ }^{20}$.

No semblen haver-se conservat més actes de nomenaments de càrrecs semblants, pero pot parlar-se d'una autentica organització basada en aquests lloctinents com a predecessors dels Comanadors ja que el 6 de juliol hom troba documentada l'actuació de fra Bernat de Monsonís com a lloctinent del

\footnotetext{
19"...quod vos sitis locumtenens seu procurator noster in castris et locis predictis ac domo predicts Valentie, et regatis, gubemetis, procuretis et administretis ad utilitatem et commodum noetri et dicti Ordinis castra et loca predicts et horhines et vasallos ipsorum, et petatis, colligatis et recipiatis seu peti, colligi et recipi faciatis universos redditus, exitus, proventus et alia in castronm et locorum ac domus predictorum, et vendatis ad unum annum si tamen discretioni vestre videbitur faciendum, in almoneta sive incanto publico plus offerenti vel offerentibus et pro quocumque pretio seu quantitate vobis melius videbitur, redditus, exitus, proventus ac alia lura castrorum et locorum predictorum..... Possitis etiam firmare in instrumentis venditionum, stabilimentorum et aliarum alienationum que iam facte sint vel fient de honoribus, censualibus ceu possessionibus que et qui tenentur pro Ordine supradicto et recipere laudimia et alia iura nobis pertinentia...." (ARV, Clergat, Montesa, lligall 867, caixa 2279-80; publica José VILAARROYA, ob.cit., 2, pp. 99-101, i Bartomeu RIBEUES, ob.cit., 2, pp. 176-178).

${ }^{20}$ ARV, Clergat, Montese, lligall 886, caixa 2333.
} 
Mestre a Culla i Ares, per negociar el pagament del salari de l'alcaid que custodiava ambdós castells. Igualment està documentada en aqueix mateix any de 1320 la presencia d'un laic, Jaume d'Anglesola, fent de lloctinent del Mestre al terme de Cervera, i que a finals d'any és substituît en el mateix càrrec per fra Arnau Pedriça, mentre l'esmentat Anglesola era convertit en simple administrador del Mestre a la susdita batllia de Cervera. També hom troba les figures de fra Sanç Pere del Ros com a lloctinent del Mestre i Prior de Valencia, la qual cosa vol dir que aquest sI que era un eclesiastic, i de fra Bernat de Roca, lloctinent a les viles d'Onda i Vilafamés ${ }^{21}$.

El primer indici d'una nova tendencia quant a l'organització interna de l'Orde de Montesa és el nomenament, fet el 31 de març de 1320 per part del Mestre, de fra Ferran Peres d'Arago, fill del futur Pere IV, com a Comanador de Perputxent. Tot $i$ aixo, el text del nomenament ens permet constatar que es tracta d'un càrrec que no coincideix amb el dels futurs Comanadors:

\footnotetext{
En axí que vós siats Comanador del dit castell (de Perputxent) e los hómens de equell castell, axí cristians com amahins mantigats e defenats donar a cade ú dret e justícia en totes coses e per totes, e demanets, cullats e reebats e dernanar, cullir e reebre fazats calònies e totes altres drets a nós pertanyens en lo castell damunt dit et en sos termes ${ }^{2}$.
}

En resum, podríem parlar d'una segona breu etapa en què va donarse una primera distribucio de funcions $i$ competencies de govern entre part dels frares no religiosos, que no tots, mentre que l'aspecte economic i de rendes senyorfvoles hom el mantingué més fortament controlat pel mateix Mestre. Aquest seria el cas d'aqueixos pobles amb un lloctinent del Mestre al capdavant -inclos l'esmentat comanador de Perputxent-, on simultàniament a la seua existència documentem com el mestre fra Arnau de Soler establia terres o molins, arrendava drets i gestionava la justícia; tot $i$ aixd, cal no oblidar que hom mantingue per sota aqueixa xarxa que hem esmentat abans, de les unitats organitzatives basades en les antigues comandes $i$ batllies de temps d'Hospitalers i Templers.

\footnotetext{
${ }^{21}$ Tots plegats apareixen en documents de l'ARV, Clergat, Montesa, lligall 895, caixa 2357, Llibre registre, s.f.

${ }^{2}$ ARV, Clergat, Montesa, lligall 867, caixa 2279-80.
} 
Una tercera etapa es donà a partir de mitjan 1321, data en què comencen a apareixer els primers nomenaments de frares com a Comanadors. No hem trobat el text corresponent de cap d'aquests, per la qual cosa potser no els podrem coneixer tots; pero gracies a les signatures que hi posaren en un document de l'Orde, amb data 4 de maig de 1321, disposem d'un primer $\mathrm{i}$ llarg llistat:

-Mestre de Montesa: fra Arnau de Soler.

-Comanador Major i Lloctinent del Mestre

a Les Coves de Vinromà: fra Berenguer de Montoliu.

-Clauer: fra Guillem Cerda.

-Comanador de Cervera: fra Erimà d'Eroles.

-Comanador de Vilafamés: fra Galcerà de Bellera.

-Comanador d'Ares: fra Ferran Peres d'Aragó.

-Comanador de Culla: fra Bernat de Monsonís.

-Comanador de Peníscola: fra Berenguer d'Erill.

- Comanador d'Onda: fra Bernat de Roca.

-Comanador de Xivert: fra Berenguer de Torrent.

-Comanador de Borriana: fra Arnau Pedriça ${ }^{23}$.

Documentació dels mesos següents ens permet identificar dos frares més de Montesa: fra Bernat d'Aramont com Comanador de Perputxent, i fra Sanç Pere del Ros, Comanador de les "cases" de Valencia; a més, des de la signatura d'un document de 9 de novembre de 1322 el Clauer, fra Guillem Cerdà, començà a ser titulat tambe com Comanador de Cervera ${ }^{24}$.

Practicament amb aquest llistat deu restar quasi completa la nomina de frares montesians no eclesiàstics en aquesta primera epoca, tot i que fer el seguiment dels càrrecs que ocuparen es fa difícil car presenten una elevada mobilitat en les comandes que ocupaven, amb ràpids i freqüents trasllats entre ells, plantejant-nos aixl un problema sobre el per que d'aquest comportament. També podem constatar com encara no sembla haver aparegut la figura del "companyo", això és, el frare admès però que no rebia cap càrrec per la falta de vacants disponibles.

Un resultat d'aquesta alta mobilitat és que, fins i tot els autors clàssics sobre Montesa com $H$. de Samper, han errat en la identificació dels

\footnotetext{
${ }^{23}$ Llistat basat en els nomenaments i títols extrets dels documents de l'AHN, OOMM, Monteas, Llibre 575c, s.f.

${ }^{24}$ ARV, Clergat, Montesa, lligall 895, caixa 2355-56.
} 
diversos frares i els carrecs que hi ocuparen al llarg del temps. Per exemple, la llista dels primers Clauers de l'Orde que citen té una equivocacio molt clara: al darrere de fra Domingo Muntanyana, nomenat Clauer a inicis del 1325, fou nomenat fra Pere de Tous el 10 de juny de 1326, a més de ser Comanador d'Onda i Sueca; pero aquest frare sols va gaudir d'aquest titol menys de dos mesos car l' 1 d'agost del mateix any fou nomenat Comanador Major; en conseqüencia, tornà a ser nomenat Clauer un frare que l'havia ocupat anys abans: fra Guillem Cerda, que fou Clauer entre l'l d'agost de 1326 i novembre del 1334.

El llistat dels primers Clauers de Montesa restaria aixf:

-fra Erimà d'Eroles (17-7-1319 a 18-1-1320)

-fra Guillem Cerda (18-1-1320 a inicis 1325)

-fra Domingo Muntanyana (inicis 1325 a 10-6-1326).

-fra Pere de Tous (10-6-1326 a 1-8-1326).

-fra Guillem Cerda (1-8-1326 a novembre 1334).

Com deiem abans, aquesta tercera etapa en la primitiva organitzacio de l'Orde de Montesa representa un pas més endavant la fragmentació de les competencies entre els seus membres, substituint els dits Lloctinents del Mestre a cadascuna de les unitats senyor/voles que conformaven el seu estat, pel model de Comandes i Comanadors que havia existit en temps de Templers i Hospitalers. Pel llistat de comanadors que hem citat pot com- provar-se com practicament l'Orde de Montesa havia reconstruït vers 1322 la xarxa jeràrquica dels seus antecessors.

Potser allo més especific és que les viles situades al voltant de la ciutat de Valencia: Sueca, Silla, Montcada, Montroi i Montesa, per unes raons o altres no foren constituïdes en Comandes autonomes sin 6 que continuaren sota el regiment directe del Mestre. En el cas de Montcada és per la seua donacio temporal al llinatge Vilanova per dues vides (fins 1358), i en el cas de Montroi no hem pogut esbrinar per que no en fou presa possessio fins el 1338.

També seria característic d'aquests primers temps que els càrrecs màxims - Comanador Major i Clauer-, encara no hi tenien una comanda o terme adscrit de forma permanent per al seu sosteniment econdmic: durant 1321-1322 el Comanador Major va tenir adscrita la batllia de Les Coves de Vinromà, i el Clauer la batllia de Cervera des del 1322, pero molt prompte els foren adscrits pobles diferents.

En 1323 el Comanador Major ja no apareix associat a Les Coves, perquè en té un de propi $i$, en ser nomenat per al càrrec fra Pere de Tous l'1 
d'agost de 1326, no li va ser assignada cap Comanda en concret de principi; un any després, el mateix frare signà documents titulant-se Comanador Major i de Cervera (23-octubre-1327) i, a les setmanes següents, en ser elegit nou Mestre, va nomenar fra Bernat de Monsonís nou Comanador Major i el féu també Comanador de Culla i Les Coves; mentre Culla va continuar associada al Comanador Major fins a la reforma organitzativa del 1330, hem documentat un Comanador de Les Coves diferent en novembre de 1328.

Quant al Clauer, si els quatre primers anys sembla associat a la Comanda de Cervera, fou a partir del 1325 quan comencem a trobar unit el càrrec a la Comanda de Sueca, mentre la de Silla -que amb el temps anirà sempre associada al Clauer corresponent- encara gaudia de Comanador propi, el mateix que el de Valencia durant 1327 i 1328 com a mínim.

D'altra banda, aquesta generalitzacio del sistema de Comanadors per jerarquitzar l'estructura interna de l'Orde de Montesa ens duu a plantejar-nos el problema de que implicava aquest títol i càrrec. Com que no s'han conservat nomenaments d'aquests anys que pogueren aportar llum sobre el tema, l'única pista acceptable seria el cas abans esmentat del Comanador de Perputxent, fra Ferran Peres d'Arag6; es tractaria per tant de competencies jurfdiques $\mathrm{i}$ de govern, tot $\mathrm{i}$ que no sembla donar-se una autonomia economica ni tampoc la gestio per separat de les rendes senyorials dels pobles que tenia assignats a la comanda.

La documentacio inclosa en el registre Mestral dels primers anys, obra del notari Pere Llobet de Balanyà, ens palesa com el Mestre, fra Arnau de Soler, continua actuant amb plens poders quant als arrendaments de les rendes senyorials de cadascun dels pobles, cobrament dels diners, lliurament de monopolis, establiment de terres, etc. arreu de totes les viles de l'Orde, incloses aquelles que en tenien, de Comanador propi; aixd és el que ens fa creure que el nomenament de fra Ferran Peres d'Aragó com Comanador de Perputxent, el qual sf que hi inclou drets economics, va ser especial, potser en raó de la categoria personal de l'individu, perque la gestió de les rendes de Montesa era controlada pel seu Mestre i els Comanadors en rebien una porció de les seues mans, no directament com passaria més endavant.

A partir del 1325 hom pot documentar algun frare arrendant les rendes senyorials de la seua Comanda, cas de fra Bernat de Monsonís, Comanador de Cervera, pero aixo ni sembla general ni pot deduir-se mecanicament que els Comanadors tingueren ja autonomia de gestio, car en el mateix any i posteriors, documentem la presencia de delegats del Mestre de 
Montesa cobrant les rendes dels pobles amb Comanador; fins i tot, un cas com el de fra Pere de Tous, Comanador Major i de la batllia de Cervera, establint un monopoli de mols fariner en favor de la vila de Sant Mateu el 23 d'octubre del 1327, pot tenir una altra explicacio: sols un parell de setmanes després moria el Mestre fra Arnau de Soler i sembla raonable pensar que som al davant d'una substitucio interina de les seues funcions, per incapacitat del Mestre, més que d'una distribució de competències i poders entre els Comanadors.

Justament sobre aqueixes problemàtiques relacions Mestre/ Comanadors disposem d'una font que il.lustra indirectament el tema; es tracta de les "Definicions" que redactaren el Mestre de Calatrava i l'abat de Santes Creus com a visitadors i corregidors de l'Orde de Montesa l'any 1326, tal com ho regulava la butlla de la seua fundacio.

En el seu text, a més de precioses notícies sobre el comportament diari dels frares quant a vestits, jocs, menjars, relacio amb dones, etc., hi ha inclosos alguns indicis sobre la necessitat de regular les funcions dels frares com tambe fins on arribava la seua autonomia de govern respecte al Mestre de l'Orde. Aixl, hom hi mana que el Mestre siga l'únic responsable en el nomenament d'oficials i carrecs al servei de Montesa, mentre que els Comanadors hauran d'encarregar-se de fer que totes les terres del seu patrimoni siguen conreades 0 , si de cas, arrendades o donades a cens. Per contra, hom hi fixa molt clarament que sols el Mestre té poders per alienar i vendre els bens del patrimoni senyorial: "ningun frayle sea osado de dar bestia, ni moro ni mora ni ganado ni pan ni aceyte ni menos vendelo sin licencia". A més a més, hi apareix també regulada la jerarquització de funcions entre Mestre i Comanadors, amb el dret del primer de controlar l'activitat dels segons: tots els Comanadors i oficials de Montesa havien de retre comptes de les seues gestions una vegada a l'any al Mestre ${ }^{25}$.

El gran canvi en l'organització interna de l'Orde de Montesa va produir-se en 1330, encetant-se aixf una quarta i més llarga etapa. Va ser el 25 de maig de 1330 quan el Capítol general de Montesa, format per més de 30 frares, es reunf a la torre de Sant Mateu, palesant ja en aquests primers anys quin era el centre polític del nou Orde militar valencià tot $i$ que el

\footnotetext{
${ }^{25}$ Vegeu James F. O'Caunghan, Las definiciones medievales de la Orden de Montesa, 1326-1468, "Miscelánea de Textos Medievales", 1 (1972), pp. 213-251.
} 
convent estiguera bastint-se a l'antic castell de la vila de Montesa, prop Xativa.

L'objectiu fonamental de la reforma aprovada pels frares fou de fer un repartiment detallat de les diverses comandes $i$, especialment, dels recursos economics i de les rendes senyorials de la Mesa Mestral i de cadascun dels Comanadors i Priors. Per que va fer-se aqueix repartiment? Els documents coetanis no palesen cap argument que en justifique aquesta reorganitzacio, per la qual cosa hem de basar-nos en allo que havia passat fins aqueix moment durant la decada de la seua existencia. És aixf com podem parlar de la forta jerarquització piramidal de l'Orde inicialment i la lenta creacio de les Comandes, les quals, tot i les limitacions en la seua capacitat d'accio, tal com ho hem constatat, logicament anirien prenent de forma diària un àmbit d'autonomia i presa de decisions per part dels seus titulars que implicaria molt probablement l'aparicio de tensions amb el Mestre de Montesa. D'altra banda, cal tenir en compte que, en bona mesura, els Comanadors foren de famlies nobles i que l'entrada en l'Orde no tenia un caràcter estrictament religiós -no esdevenien eclesiàstics-, per la qual cosa el seu caràcter de cavallers que aconseguien una posició social mercès a ferse Montesians esdevenia fonamental; aixo vol dir que, sens dubte, molt prompte degueren encetar-se les reclamacions contra el Mestre per aconseguir la garantia d'uns recursos economics que pogueren considerar com a propis i que no foren mediatitzats per la intervenció del Mestre, a més a més quan en els darrers anys s'havia produït la generalització del nomenament de Comanadors. Sembla logic pensar que aqueixos Comanadors devien pressionar per aconseguir uns guanys fixos.

Considerem il.lustrativa la participacio de frares en el Capitol que aprovà la reforma: dels 20 frares cavallers, sense comptar el Mestre, i dels 13 frares eclesiàstics, en bona part residents al Convent de la vila de Montesa, assistiren a la reunió tots els cavallers llevat d'un, i sols un d'eclesiàstic, el Prior del mateix Mestre ${ }^{26}$.

El repartiment de les rendes senyorials Montesianes significà l'assegurança a tots els frares d'uns ingressos propis i autonoms, els quals rebien directament sense dependre de la bona voluntat del Mestre; és per aixd que podem parlar d'una pèrdua per part d'aquest d'una part del seu poder sobre

\footnotetext{
${ }^{26}$ AHN, OOMM, Montesa, llibre 575c, fol. 79-85, i fol. 201-206; publica José ViLLARROYA, ob.cit., 2, pp. 140-151.
} 
el conjunt de l'Orde i que va encetar-se un nou perfode en la historia de Montesa no tan piramidal en la seua estructura interna.

Bàsicament les rendes foren repartides en tres apartats: un de primer, el Mestre amb la Mesa Mestral, a la qual foren assignades les rendes de la batllia de Cervera; era aquesta la més poblada, tal com hem vist abans, i per tant la que aportava els ingressos més considerables.

Un segon bloc de rendes fou assignat als Comanadors pero no amb allo que serà comú a partir del segle XV, aixo és, que cadascun d'ells disposara del valor total de les rendes de la seua Comanda i abonara una part minoritària, fixa i anual, a la Mesa Mestral. En aquesta reforma del 1330 es va fer al contrari: el Mestre continuà arrendant totes les rendes senyorials, incloses les Comandes, i hom fixà una quantitat anual a cobrar sobre els susdits arrendaments per a ser pagada al cavaller corresponent.

En rao de la riquesa de cadascuna de les Comandes va fer-se el següent repartiment:

-Comanador de Peníscola: 7.000 sous/any.

-Comanador de Xivert: $4.500 \mathrm{~s}$.

-Comanador d'Onda: $4.500 \mathrm{~s}$.

-Comanador de Culla: 4.000 s.més rendes d'unes poques terres del terme i la sofra dels moros.

-Comanador de Les Coves: $4.000 \mathrm{~s}$.

-Comanador d'Ares: $3.500 \mathrm{~s}$.

-Comanador de Vilafamés: $3.500 \mathrm{~s}$.

-Comanador de Borriana: $3.500 \mathrm{~s}$.

- Comanador de Perputxent: uns 2.000 s., perque del seu arrendament ha de donar-se anualment $3.500 \mathrm{~s}$. al Clauer per al sosteniment del Convent.

És aquest darrer frare, el Clauer, el que no apareix amb major detall en el repartiment d'ingressos $i$ aixo no més pot tenir com explicació el fet que en aquesta primera epoca no tenia les funcions i l'equivalencia a un Comanador que va tenir des del final del segle XIV. A hores d'ara sembla un delegat del Mestre encarregat de fornir els queviures, robes, ornaments, etc. que calguen per als frares religiosos del Convent de la vila de Montesa, tot a les ordres del Mestre $i$ amb el probable subministrament de diners corresponent. Prova d'aixo és una afirmació d'un dels acords d'aquest Capitol del 1330 arran de l'estada del Clauer en funcions guerreres a la frontera: "Que al Clauer, que no ha provisio, hage per quatre meses que estigué en la frontera....duo milia solidos". 
Resta sense aclarir la destinació de les rendes de tres viles situades a l'horta de Valencia: els béns de la mateixa Ciutat, i les de Silla i Sueca, a més dels casos ja argumentats de Montcada i Montroi. El text no cita cap d'aquestes viles, pero hem documentat que entre 1327 i si més no fins 1333 fou comanador de Valencia i Silla fra Pere Çes Olives, que era religiós i no frare laic com la resta de Comanadors, la qual cosa ens fa pensar si aqueixa condició eclesiàstica fou la causa que no se li assignaren rendes en aquell moment; aixo voldria dir que les rendes de Silla, Sueca i Valencia restarien dins els ingressos de la Mesa Mestral.

Finalment, va acordar-se en aquell Capitol del 1330 fer una tercera porció dels ingressos generals de l'Orde de Montesa per mantenir un "Fons Comú", gestionat per dos tresorers elegits entre els Comanadors existents; aqueix fons era nodrit amb els diners que sobraven de l'arrendament de cadascuna de les Comandes, una vegada abonada la part estipulada al seu titular, i tambe amb les entrades o preus pagats per establiments de terres, cases $i$ monopolis en la batllia de Cervera; a més, calia afegir el morabatf $i$ troballes per tots els pobles de la senyoria, $\mathrm{i}$ les redempcions monetàries per no anar a la host i cavalcada quan n'eren convocades les viles.

L'existencia d'aquesta caixa comuna implicava que els frares Comanadors podien rebre més ingressos respecte els fixats mitjançant la seua Comanda. Va ser estipulat que quan foren "a la frontera", la qual cosa vol dir anar a la guerra, rebrien del fons comú 200 sous al mes per soldada, $i$ cas d'haver-hi carestia en rebrien més; si perdien els cavalls a la guerra els els pagaria l'Orde, com també les armes i cavalls dels frares companyons que tenien associats cadascun d'ells. A més a més, sembla deduir-se de l'acord pres pel Capitol del 1330 que els Comanadors rebrien els ingressos de les multes (calonies), lluïsmes, fadigues i drets d'establiment de terres $\mathrm{i}$ béns en la seua respectiva Comanda, mentre que el Mestre es comprometia a pagar del fons comú les despeses dels plets judicials en que hom trobara compromesa l'Orde com a col.lectivitat.

Podria deduir-se d'una primera lectura i de la versió dels fets que apareix en els autors classics -Samper i Villarroya-, que en aquest Capítol va fer-se un repartiment equilibrat de les rendes entre el Mestre, els Comanadors $\mathrm{i}$ el fons comú $^{27}$; la realitat, perd, sembla prou distinta perque aqueix repartiment no té com a objectiu racionalitzar el funcionament de

${ }^{27}$ Com afime tambe Luis GARClA-GuUarRo, ob.cit., p. 38 i p. 133. 
l'Orde de Montesa sinб acontentar una primera onada de reivindicacions dels frares Comanadors enfront del poder Mestral.

Cal tenir en compte que, tot i no ser citat més que ocasionalment, hi havia un quart i important destinatari de les rendes de l'Orde: el convent de Montesa, el qual devia reunir possiblement ja en aquest temps els ingressos senyorials de la mateixa vila de Montesa, potser els de Sueca, i els $3.500 \mathrm{~s}$. assignats sobre les rendes de Perputxent, a més de les quantitats que el Mestre poguera aportar de la part corresponent a la Mesa Mestral.

Un punt important és intentar aclarir en diners què significava aqueix repartiment proporcional de les rendes de l'Orde; segons l'acord, als Comanadors els són atribuïts uns $\mathbf{3 8 . 0 0 0}$ sous a l'any, pero, quant era aixo respecte el total dels ingressos de Montesa?

No coneguem els seus ingressos totals en aquest any, car la documentació de comptabilitat ha desaparegut totalment per a l'epoca medieval,' pero podem intentar fer-ne un balanç aproximat a partir de la valoració de les rendes de cadascuna de les viles de la senyoria en 1320, a més dels ocasionals valors dels arrendaments conservats fins al 1326 en el llibre registre del Mestre fra Arnau de Soler ${ }^{28}$.

Sense ser exhaustius, ja que són incontrolables les quantitats procedents de multes, lluïsmes, etc., hom pot fer un balanç d'uns 175.000 sous com a mínim, per any, d'ingres ordinari de l'Orde de Montesa en aquella epoca. D'aquesta xifra podem deduir la part assignada als Comanadors, fixa anualment, i que arribava als esmentats 38.000 sous, la qual cosa vol dir sobre un $22 \%$ del total; sumant els valors coneguts de les rendes dels pobles de la batllia de Cervera en aqueixos anys -assignada a la Mesa Mestral-pertocaven al Mestre uns $\mathbf{4 0 . 0 0 0}$ sous anuals, la qual cosa ve a ser un $23 \%$ del total d'ingressos. El Convent de Montesa, amb les assignacions de les rendes de la vila de Montesa, probablement Sueca i potser Silla i Valencia a més del 3.500 sous de Perputxent, sumava uns 29.000 sous com a maxim, un 16 o $17 \%$ del total aproximadament; tot $i$ aixo, el repartiment d'ingressos entre la Mesa Mestral i el Convent degué ser relativament indiferenciat en aquests anys: el Mestre aportava quantitats segons les necessitats del manteniment conventual, especialment les obres de construcció del convent -del qual no tenim ni una referencia-, $i$ tot fa creure que la part proporcional Mestral fou sens dubte més considerable, si més no quant al seu control.

\footnotetext{
${ }^{23}$ ARV, Clergat, Montesa, lligall 895, caixa 2357.
} 
Aquestes quantitats, sempre arrodonides i partint de la base quantitativa de la decada del 1320 , deixaven uns 65.000 sous per al fons comú, que venia a ser un 37 o $38 \%$ del total aproximat; d'aquests, 40.000 sous anuals, pero, eren pagats al Patriarca d'Alexandria per decisio del Capitol. En teoria, per tant, podríem parlar d'un repartiment semblant entre el Mestre i els 9 Comanadors reconeguts, amb quasi un quart de les rendes per a cadascú, perd amb un altre $16 \%$ més dedicat al Convent de la vila de Montesa el qual era en la pràctica gestionat pel Clauer $i$ controlat en darrera instància pel Mestre.

I encara podem valorar una realitat més: en la pràctica, el Mestre era qui decidia en què hom gastaria el fons comú, efectivament lliurant quantitats als Comanadors pero també per a despeses internes -viatges a la frontera per raб de guerra, les obres del convent esmentades?- o externes -plets, donacions al Patriarca, etc.-, en nom i benefici de l'Orde com a col.lectiu, Orde que tenia logicament en ell la seua màxima representacio dins l'àmbit de la vida pública de la Corona.

Aquest panorama és el que ens fa afirmar que amb aquesta gran reforma del funcionament intern del Orde de Montesa del 1330 el Mestre continuà sent qui controlava clarament la jerarquia de poders al seu si; el que si és cert és que havia estat produïda una escletxa en aqueixa jerarquia en favor dels Comanadors titulars, pero recordem que aquests no son tots els frares de Montesa. Ni els frares eclesiàstics semblen tenir cap poder dins la jerarquia de l'Orde -i un altre tema apassionant és el de la jerarquia de Priorats i del món del Convent-, ni tampoc la resta de frares cavallers -onze, si ens atenem a la nomina d'identificats en el Capitol de 1330- havien millorat amb aquesta reforma.

Aquests darrers frares, anomenats companyons o "socii", representen el grup dels que han estat admesos pero que es troben a l'espera d'una vacant en les comandes existents, tema complicat ates el reduït nombre d'aquestes. Els fets palesen que en aqueixa primera decada havien estat admesos un nombre de frares -sobre la vintena- que potser encaixaven amb una estructura d'Orde militar tradicional, amb diversos frares en cadascuna de les comandes existents. És el que havien fet fins aquesta època l'Orde de l'Hospital i el del Temple; pero quan Montesa començà a crear comandes vers 1324, aquestes semblen esdevenir molt rapidament el patrimoni economic dels frares que puguen ser els seus titulars. Logicament aixo significava diferenciar en dues categories molt netes els frares de l'Orde, i tambe pensem que entrebancava la seua estructura tradicional. El problema, a partir 
de la reforma del 1330, era que calia fer amb un "excés" de frares cavallers en proporcio al nombre de comandes possibles i sense que el Mestre perdés la seua porció important d'ingressos.

Pensem que una de les respostes que es donaren fou la creacio del fons comú, pero més en concret va procedir-se a l'adscripció dels diversos frares companyons entre cadascuna de les comandes, amb l'aprovacio de menudes quantitats anuals de diners en llur benefici com també el pagament de cavalls i armes per part del fons comú: "Item, lo Comanador d'Ares, tinent aquella haja de provisio ab un frare cavaller al qual haja a tenir bestia et missatge e ab tota sa companya..."; de fet, pero, la seua situació sembla molt dependent de la voluntat personal del Comanador del qual havien estat fets "socii". Cal pensar que, qui havia protagonitzat el Capitol reformista, havien estat els Comanadors i no pas la resta de frares: "Item, que'ls Comanadors sien tenguts de proveir bé e covinentment los frares companyons, segons que per declaracions del Orde ya feytes és ordenat e declarat, e que paguen les companyes complidament e en manera que non puga dany venir al Orde".

D'aquesta manera, des del 1330, l'estructura organitzativa de l'Orde de Montesa va restar aixf:

-el Mestre té assignada la batllia de Cervera.

-el Comanador Major, la Comanda de Peníscola.

-el Clauer, la de Sueca.

-son comandes individuals, les d'Ares, Culla, Les Coves, Xivert, Vilafamés, Onda, Borriana i Perputxent.

-les rendes de Castellfabib i Ademús formen un Priorat.

-Montcada i Montroi seguien provisionalment fora del control de l'Orde.

-adscrites al Convent: la vila de Montesa, i probablement les rendes de Silla i Valencia.

A partir d'aquesta reforma, sembla que l'Orde va mantenir aquesta estructura d'una forma bàsica, tot i que va anar evolucionant lentament amb el temps. Es fa problemàtic, pero, poder identificar correctament cadascun dels canvis que s'hi donaren car hi ha amples buits documentals per al segle XIV.

Que el repartiment de competencies i poders entre el Mestre i els Comanadors no fou estable ni harmonic ho palesen alguns fets aillats, com l'enfrontament de l'any 1353 quan el rei Pere el Cerimonios i el Mestre fra Pere de Tous negociaren i arribaren a redactar uns Capitols pels quals era 
dissolt l'Orde i el seu patrimoni i els frares serien inclosos dins l'Orde de Sant Joan de l'Hospital ${ }^{29}$.

La historia d'aquests fets no és gaire coneguda, pero els textos semblen indicar una actuació ainlada del Mestre, fra Pere de Tous, tan sols recolzat pel seu germà, fra Albert de Tous, acabat de nomenar Comanador Major. L'actitud de la resta dels frares Comanadors sembla que va ser rotunda en contra del projecte $i$ empraren el mecanisme de reaccio al seu abast; aixo és, convocaren un Capitol General de l'Orde de Montesa en desembre del mateix any, 1353, i prengueren diversos acords en contra de la seua desaparició $\mathrm{i}$ integració en l'altre Orde; a més, obligaren el Mestre Tous a defensar-los davant el monarca ${ }^{30}$.

Bé siga conseqüència d'aquest tipus de problemes quant a l'enfrontament de tipus politic entre els Mestres fra Pere i fra Albert de Tous durant bona part del segle XIV, bé siga com a resultat dels probables problemes economics que tindrien a poc a poc els Comanadors arran de la devaluacio de les seues rendes, que eren fixes, recordem-ho, bé siga probablement per ambdues raons, allo cert és que a partir de la década del 1380 constatem documentalment un gran canvi quant al repartiment de les rendes senyorials de Montesa entre els membres de l'Orde.

Ja antigament, un autor clàssic montesià com Villarroya va constatar aquest fet: "...tiempo después del Primer Capítulo General se fueron enriqueciendo las Encomiendas, con haberse aplicado a los Poseedores todos sus frutos y emolumentos..." ${ }^{31}$. Tot $\mathrm{i}$ no datar cronologicament aqueix "tiempo después", aquest autor apunta el fet de la probable desaparició del "Fons Comú" i dels Tresorers conseqüents, i assenyala a més el tomb total que hom havia produït en el mecanisme intern de repartiment de la renda feudal aconseguida per l'Orde de Montesa.

Durant l'any 1380, el nou Mestre fra Albert de Tous va procedir a renovar un ample llistat de Comanadors, efectuant els conseqüents nomenaments; gràcies al text d'aquests hem pogut documentar el mecanisme de repartiment de les rendes de cadascuna de les respectives comandes; en concret, els sistema de repartiment de les rendes entre el Mestre i els Co-

\footnotetext{
29 Aurea Javierre MUR, Pedro $N$ el Ceremonioso y la Orden de Montesa, "Miscelánea J.E. Martínez Ferrando", 1968, pp. 197-216.

${ }^{30} \mathrm{AHN}$, OOMM, Llibre 575c; publica Aurea JAvierRe, Pedro IV el Ceremonioso.

${ }^{31}$ Jose VILLARROYA, ob.cit., 1, p. 168.
} 
manadors havia tombat 180 graus ja que és el contrari al sistema aprovat pel Capitol del 1330: ara els Comanadors pagaven una quantitat fixa preestablerta al Mestre de Montesa i ells es quedaven la resta dels ingressos, la qual cosa vol dir que podien beneficiar-se del creixement de les rendes $i$ aprofitar qualsevol canvi en la gestio corresponent per augmentar els seus ingressos particulars. Sens dubte, aquest tomb només pot ser resultat de la pressio dels frares Comanadors per augmentar la seua part proporcional en les rendes de l'Orde, i palesaria aix I la tendencia vers un enfortiment del seu poder al si de la jerarquia interna de Montesa.

El llistat de nomenaments esmentat ens permet concretar les següents quantitats de pagament al Mestre anualment:

-Comanda de Les Coves de Vinromà: 12.000 sous.

-Comanda de Culla: 6.000 sous.

-Comanda de Xivert: 4.500 sous.

-Comanda d'Onda: 4.000 sous.

-Comanda d'Ares: 3.000 sous.

-Comanda de Vilafames: 3.000 sous.

-Comanda de Perputxent: 3.000 sous $^{32}$.

Com podem veure manca informació de dos Comandes, Borriana i Valencia, com també de les rendes del Comanador Major i del Clauer, pero l'evidencia del nou sistema de repartiment de rendes és clar, amb el pagament d'aquesta "responsi 6 " anual al Mestre.

Més diff́cil és calcular la proporció d'aquests ingressos respecte a les rendes totals de l'Orde de Montesa a la darreria del segle XIV. La manca de comptabilitat senyorial no permet generalitzar, pero hem pogut documentar un cas que podria servir d'exemple. La Comanda de Les Coves de Vinromà tenia una renda feudal aproximada en 1330 d'uns 20.000 s., tal com ho hem indicat abans; d'aquests, el Capitol va fixar $4.000 \mathrm{~s}$. com a renda del Comanador i, logicament, el $80 \%$ restant correspondria al "Fons Comu" controlat pel Mestre. Doncs bé, l'arrendament d'aqueixa comanda per als anys 1396-1397, segons el text d'un censal carregat pel seu Comanador, fra Guillem de Vilafranca, el 27 de març de 1397, va pujar a 24.000 sous per any ${ }^{33}$.

\footnotetext{
${ }^{32}$ Basat en dades extretes d'AHN, OOMM, Montesa, Llibres 828c i 832c.

${ }^{33} \mathrm{AHN}$, OOMM, Montesa, Llibre 832c, s.f.
} 
Aixo vol dir que si la "responsio" al Mestre era en aqueix any de 12.000 sous, l'altra meitat de les rendes eren per al Comanador. En comptes senzills, la renda d'aquest darrer havia restat multiplicada per tres al llarg del segle XIV, i sembla raonable considerar si més no una tendencia semblant per a la resta de Comanadors. A més a més, atès el creixement global de les rendes al llarg del segle XIV, aixo voldria dir que, tot i aquest repartiment més favorable als Comanadors, l'ingrés global dels Mestres també degué créixer favorablement.

Més problemàtic és parlar del futur al llarg del segle XV; justament des de la darreria del segle anterior constatem l'inici dels trets de la crisi general del sistema feudal, com ara els problemes demografics $i$ cert afonament de les rendes senyorials. Aixo potser implicà que amb el pas del temps, mentre la renda per a la Mesa Mestral, essent fixa, mantingué part del seu valor, tota caiguda de les rendes globals de cadascuna de les Comandes repercutiren directament sobre el Comanador respectiu, pero aquesta tendencia a la seua debilitat se'ns escapa a hores d'ara perquè no tenim més fonts.

Centrant-nos en el segle XIV, aquestes dades de tipus economic ens fan creure que els Comanadors aconseguiren anar reforçant la seua posició al llarg d'aqueix segle, mitjançant el control de la gestió autonoma de les seues Comandes, enteses no pas com a delegacions del poder del Mestre sino com a unitats independents, menudes senyories particulars de cadascun dels Comanadors, i d'on treien el màxim profit possible.

Diferent és la consideració de si aconseguiren avançar de la mateixa manera a nivell del repartiment de poders dins l'Orde de Montesa. I tot ens fa creure que no, que no hi hague un paral.lelisme entre repartiment economic i repartiment del poder al si de l'Orde. A més a més, fins i tot no és tan clar que el tomb en el sistema de repartiment de les rendes de les Comandes siga directament en contra dels interessos economics del Mestre. Més bé sembla que la víctima en fou l'anomenat "Fons Comú" i que va produir-se una bipolarització entre Mestre i Comanadors. En concret, arran de la incorporació de la vila de Montroi a l'Orde el 10 d'octubre de 1338, el seu beneficiari fou la Mesa Mestral ${ }^{34}$, i el mateix va passar amb la molt més rica batllia de Montcada, a l'horta de Valencia. Mort en Vidal de Vilanova el.1358, usufructuari d'aquests pobles segons els textos fundacionals,

\footnotetext{
${ }^{34}$ ARV, Clergat, Montesa, lligall 885, caixa 2329.
} 
immediatament va ser assignada pel Papa Innocenci VIe al Comanador Major, fra Albert de Tous, com a patrimoni personal de nou per la seua vida ${ }^{35}$; no fou fins a la seua mort en 1382 quan la batllia de Montcada restà inclosa a la Mesa Mestral com a patrimoni propi, no pas personal, del Mestre de torn, pero aixi va perdurar posteriorment.

Al llarg del segle XIV també podem parlar de la consolidació del poder personal de la figura del Clauer de l'Orde. Cal recordar que, arran de la seua fundacio, li fou assignada la funcio de manteniment material del convent a bastir a la vila de Montesa, per a la qual cosa hom li feia lliurament de les rendes de la vila de Sueca com a administrador seu, pero no hi ha cap indici de que aixo implicara la categoria de Comanador de Sueca; aquest és un titol que no és emprat durant aquestes primeres decades.

Poc després del conflicte de la Unio, entre 1350 i 1353, se li va adscriure el titol de Comanador de Silla, potser com a renda personal per a qui ocupara el càrrec. És raonable aquesta possibilitat perque en 1390 apareix el Clauer signant els documents també amb el titol de Comanador de Sueca, Silla i Montroi; concretament, el 18 de maig del 1390 el Mestre fra Berenguer Marc va anomenar fra Sanxo d'Espejo nou Clauer, detallant el nomenament que les rendes de Sueca eren per a les despeses del Convent mentre les de Silla i Montroi eren per a la seua despesa particular ${ }^{36}$.

Tot $i$ aixo, fets aillats ens permeten sospitar que la no clarificacio neta de les rendes assignades a cadascun dels carrecs implicava la possibilitat de que foren emprades en benefici particular del Mestre en un moment donat; és aix I com en 1385 el Mestre fra Berenguer Marc va nomenar el Clauer, fra Bernat de Basella, com a Comanador i administrador de la batllia de Montcada en el seu nom i de forma temporal per millorar la gestio, pero aixo no implicà la separació de dites rendes de la Mesa Mestral; igualment, el 2 de novembre del 1395, el susdit Mestre va llevar les rendes de Montroi al Clauer i les va donar en pagament d'un préstec, disposant d'elles segons les seues necessitats ${ }^{37}$.

D'altra banda, cal que tinguem en compte l'existencia de rendes irregulars i/o extraordinàries que pogueren arribar ocasionalment a mans de

\footnotetext{
"Seregrín L. LLORENS RAGA, La Orden de Moniesa en el Reino de Valencia duranie el siglo XIV, "VIII Congreso de Historia de la Corona de Aragón", II-2, 1967, p. 322.

${ }^{36} \mathrm{AHN}$, OOMM, Montese, Llibre 828c, s.f.

${ }^{37}$ AHN, OOMM, Montesa, Llibre 832c, s.f.
} 
l'Orde de Montesa, i més en concret a mans del seu Mestre. Potser un cas especial, pero que no deixa de ser il.lustratiu, és la guerra de la Unio, la revolta encapçalada per la ciutat de Valencia i que per raons especifiques tingue un resso de revolta antisenyorial en les terres de l'Orde de Montesa durant 1348 i 1349 . La derrota dels vassalls permeté al Mestre establir un considerable castig econdmic en multes sobre ells, de desenes de milers de sous, pero tingue també una repercussio més duradora tot i que no fóra tan elevada a curt terme.

Es tracta de l'apropiació de la renda anomenada "mitja primícia" per part del Mestre en els pobles d'Ares, Salzadella, Vilanova d'Alcolea, Culla, Benassal, Vistabella, Atzeneta del Maestrat, Benafigos, Boi, Molinell, Vilar de Canes i Torre d'en Besora ${ }^{38}$. Segons els textos de les cartes de poblament del segle XIII, atorgats a fur d'Arago, la primícia pagada a la parroquia local no pertanyia al bisbe de Tortosa sino al consell local per a les despeses de l'església veïnal; arran de la Unio, el Mestre de Montesa va castigar aquestes viles amb la perdua del control d'aquest pagament i se'l va apropiar com a ingrés de la Mesa Mestral. En el futur pogueren atorgar alguna d'aquestes rendes a diverses persones, pero no hi hague dubte en la seua adscripció definitiva a la persona dels Mestres.

Un altre cas semblant és el de la Torre de Vinrobf, posteriorment coneguda com Torre d'en Besora; pertanyent a un menut llinatge catala, els Besora, des dels anys del repoblament en el segle XIII, va ser comprada pel mestre fra Albert de Tous entre 1371 i 1372; poc després, el 23 d'octubre de 1373 , ja hem documentat al susdit Mestre arrendant per 2.000 sous/any les rendes del lloc esmentat i disposant del seu ingrés en els anys posteriors, integrades entre les de la Mesa Mestral ${ }^{39}$.

De la mateixa forma hem pogut documentar a la darreria del segle XIV, concretament en juny del 1393, com $\in$ l Mestre també s'havia apropiat durant els anys anteriors de les rendes corresponents a l'Orde de Montesa en les viles d'Ademús i Castellfabib; en aqueix any eren valorades en 5.000 sous anuals, quantitat ben significativa ${ }^{40}$.

Fins i tot, a la darreria del segle XIV constatem la vigencia del costum que tots els béns materials dels frares montesians morts corresponien

\footnotetext{
"AHN, OOMM, Montesa, llibres 542c i 543c.

"Arxiu de Protocols del Patriarca de Valencia, notal 3.

${ }^{\infty} \mathrm{AHN}$, OOMM, Montesa, Llibre 832c, s.f.
} 
a l'Orde, tal com hom ho establia en les Definicions o estatuts fets pels visitadors del Císter; logicament era el Mestre de Montesa qui, posteriorment, liquidava $i$ disposava d'aqueixos béns en nom del col.lectiu que encapçalava. Conseqüencia també d'aquesta jerarquia de funcions era el fet que, quan moria un frare Comanador, era el Mestre qui rebia provisionalment les rendes de la comanda fins al dia en què era nomenat un successor per ell mateix. La perversió del sistema és senzilla de suposar: endarreriments més o menys indissimulats en la provisió de les Comandes vacants; en agost de 1394 el mestre fra Berenguer Marc nomenà un collidor de les rendes de Xivert arran de la mort del darrer comanador i d'haver-se-la reservada, $i$ en juliol de l'any següent féu el mateix amb la comanda de Peniscola: les rendes corresponents va dedicar-les d'immediat a liquidar diversos deutes ${ }^{41}$.

Podem constatar les queixes per aquest comportament dels Mestres en les intervencions dels Visitadors calatraus, els quals manaren la fi d'aqueixos comportaments i l'obligació dels Mestres de nomenar ràpidament un nou Comanador.

Finalment, podem comprovar com a la darreria del segle XIV els Mestres de Montesa aconseguiren generar una nova via d'ingressos en benefici seu i a costa de tots els vassalls de la seua senyoria. Es tracta dels impostos directes i extraordinaris sota la forma de peticions economiques per causes concretes; aixf, en 1384 el Mestre va nomenar un administrador per rebre i recaptar els 70.000 sous que tots els pobles de l'Orde de Montesa li havien "ofertat" en la seua ajuda i com col.laboració "voluntària" a mantenir les despeses $\mathrm{i}$ liquidaci 6 de deutes del Maestrat ${ }^{\mathbf{2}}$.

No és aquest sistema una excepcio ni una peculiaritat dels montesians, car el tenim documentat al llarg de la segona meitat del segle XIV i posteriorment tant en altres senyories valencianes com per part de la monarquia; tot i la major dificultat d'aconseguir identificar els casos en que va ser demanat, a hores d'ara sabem que foren peticions fiscals extraordinàries prou habituals i que representaren una autentica "revolucio" fiscal juntament amb altres elements, ja que aconseguiren aixl revifar les rendes ordinàries

${ }^{41} \mathrm{AHN}$, OOMM, Montesa, Llibre 832c, 8.f.

${ }^{42} \mathrm{AHN}$, OOMM, Montesa, Llibre 828c, 8.f. 
tradicionals de les senyories i de la corona, afectades per una caiguda significativa a partir d'aquestes dates ${ }^{33}$.

Dins el context de les relacions de poder al $s i$ de l'Orde de Montesa, el pas del segle XIV al XV ens permet constatar un fet: la teorica comunitat de frares que conformaven l'Orde militar en els anys de la seua fundacio pot dir-se que havia desaparegut. D'una banda, els Comanadors havien enfortit la seua posicio econdmica i adhuc juridica havent aconseguit fer de les comandes unitats senyorivoles, fiscals i de gestio practicament autonomes $i$ liquidant tan sols una quantitat de diners a l'any en favor del Mestre; d'altra banda, pero, aquest mantenia el control directe sobre una ampla base territorial, la Mesa Mestral tot $i$ que aquest mot no és emprat encara aleshores, la qual presenta una composició bàsica entorn del territori de la batllia o setena de Cervera, amb la gran vila de Sant Mateu com a capital i localitzacio del palau Mestral; a aquests calia afegir durant aquest segle XIV el control més o menys directe sobre les viles i rendes de Montcada i Montesa, i fins i tot de Silla, Sueca i Montroi, indirectament mitjançant la figura del Clauer, tot $i$ que aquest darrer va accedir progressivament a una total autonomia que el va equiparar, ja en el segle XV, a la resta de Comanadors quant a la seua relació amb el Mestre de l'Orde.

A més a més, tal com ho hém explicat, la Mesa Mestral va reunir també en aquesta epoca medieval un ventall dispers de rendes locals, com ara les del menut lloc de la Torre d'en Besora, la mitja primícia de vàries viles, les provisions de les comandes vacants $i$ els subsidis i peticions fiscals extraordinaris, molt elevats de vegades; amb un altre origen caldria incloure ingressos irregulars per part dels Mestres, procedents de donacions personals fetes pels monarques de la Corona d'Arago atès la seua participació en activitats militars, polítiques i diplomàtiques al servei de la Corona, quantitats molt diff́cils de quantificar i coneixer en base a la documentacio coneguda actualment, pero que no considerem com irrellevants.

Als inicis del segle XV, l'organitzacio interna de Montesa i les viles senyorials assignades a cadascun dels frares seria la següent:

-Mestre: Batllia de Cervera i batllia de Montcada, a més de les rendes d'Ademús, Castellfabib, Torre d'en Besora i altres irregulars.

-Comanador Major: Comanda de Peníscola.

\footnotetext{
${ }^{43}$ Vegeu Enric GUINOT RODRIGUE2, El Patrimoni Reial al Pais Valencid a inicis del segle XV, "Anuario de Estudios Medievales", 22 (1992), pp. 581-639.
} 
-Clauer: Sueca, Silla i Montroi, tot i que sols les dues dạrreres són per al seu benefici ja que les rendes de Sueca són per a la despesa del convent de la vila de Montesa.

-Sotsclauer: Montesa i Vallada.

-Comanadors: Ares, Culla, Les Coves de Vinroma, Xivert, Onda, Borriana, Perputxent.

-Priorat de Valencia: rendes de la ciutat de Valencia.

Durant el segle XV aquest organigrama va mantenir-se bàsicament estable, cas de l'existencia de les comandes o les proporcions en el repartiment d'ingressos entre Comanadors i Mestre; tot $i$ aix $\partial$ va donar-se alguna modificacio en l'adscripció del titol de Comanador Major, i més per raons externes que internes al repartiment de poders de Montesa.

Prova de la poca existencia de trasbalsaments organitzatius es que la incorporacio a Montesa del petit Orde militar de Sant Jordi d'Alfama, decretada per butlla Papal el 1400 , va implicar poca cosa més que l'honor, el titol afegit al nom de l'Orde i la substitució simbolica de la creu negra tradicional de Calatrava per la més senzilla i roja de Sant Jordi com a senyal distintiu extern. Pràcticament en fallida economica l'Orde de Sant Jordi aquesta és la raó de la seua incorporacio a Montesa-, el Mestre fra Berenguer Marc sols va fundar un Priorat -que no comanda- al Coll de Balaguer, als límits septentrionals del terme de Tortosa i vora la mar, on havia existit tradicionalment un menut monestir que havia estat la rao de la fundacio de l'Orde de Sant Jordi. Les dificultats d'aconseguir alguns eclesiastics disposats a residir en aqueixa zona apartada i despoblada -amb la justificacio de les poques rendes assignades- varen fer que la seua existencia dins l'Orde de Montesa no arribara a mig segle i, a mitjans del segle XV, constatem la desaparició d'aqueix Priorat en la seua estructura interna.

D'altra banda, arran dels conflictes del Cisma d'Occident, el Papa Luna, Benet XIII, va rebre la protecció del rei Mart/ en els seus estats i, arran de la mort del Mestre de Montesa, fra Berenguer Marc, en 1410, el dit Papa aprofita l'avinentesa per imposar un nou Mestre fidel a la seua persona, fra Romeu de Corbera; a més a més, atesa la seua jerarquia religiosa sobre l'Orde, va aprofitar el moment de feblesa en l'organització Montesiana i va redactar una butlla incorporant la vila i el castell de Peniscola a la Santa Seu i com a residencia personal. Indirectament aixo va fer que el Comanador Major, fra Berenguer Domenge, perdera part important dels seus ingressos, tot $\mathrm{i}$ que els llocs més menuts de Vinaros i Benicarlo restaren sota el seu control; per la qual cosa el dit Comanador major va 
demanar al Mestre que el mantinguera com a titular de la comanda de que havia gaudit fins aleshores, la de Culla; efectivament, el dia 1 de juny de 1414 el Mestre va procedir a la seua adscripció com a nova comanda annexa al càrrec de Comanador Major"

És interessant constatar com la incorporacio de Peníscola al Papat en 1410 va ser també aprofitada pel Mestre de Montesa, fra Romeu de Corbera, per augmentar els seus ingressos i recursos; les viles de Benicarló i Vinaros, separades de l'antiga comanda de Peníscola, foren aixi incorporades a la Mesa Mestral durant tota la llarga vida d'aquest Mestre, fins a la meitat del segle XV.

Després de diverses alternatives en la situació de Peníscola, convertida en vila reial en 1427 , va ser venuda amb pacte de retrovenda al Mestre de Montesa en 1441, i va ser igualment incorporada a la Mesa Mestral, tot i que probablement aixo va empenyer el Mestre a crear una nova comanda anomenada de Vinaros i Benicarlo; el seu titular el tenim documentat a partir de 1450 aproximadament, el qual, ates que no tenia unes rendes senyorials tan elevades com en temps anteriors a la segregació de Peníscola, va aconseguir que se li perdonara tot pagament anual en favor del Mestre, tal com ho feien la resta de comandes ${ }^{45}$.

Dels mateixos anys, cinquena decada del segle XV, és l'aparició en els documents de l'Orde d'un titulat Comanador de Castellfabib i Ademús, el qual va veure fixada una contribucio o responsio anual de 500 sous en favor de la Mesa Mestral; pero aquest càrec no va consolidar-se i va fluctuar en el temps la seua existencia segons la bona voluntat del Mestre corresponent.

Quant a la Mesa Mestral com a tal, durant el segle XV mantingué la seua base territorial sobre les dites viles de Sant Mateu i tota la batllia de Cervera, a més de la de Montcada $i$ les rendes disperses que n'hem citat abans; en 1410 incorporà també les viles citades de Vinaros i Benicarlo, i es produr un nou canvi a partir de l'l de setembre de 1441: Vinaros i Benicarló foren fetes comanda, com hem dit, pero la reincorporacio de Peníscola fou en benefici dels Mestres montesians; aix perdurà fins al 30 de juliol de 1488, quan el rei Ferran el Catolic reunf els diners per recomprar aquesta vila, pero durant els quaranta anys intermedis Peníscola fou governada per

\footnotetext{
${ }^{4}$ Hipdlit de SAMPER, ob.cit., 2, p. 415.

${ }^{45}$ ARV, Clergat, Montesa, lligall 867, caixa 2279-80.
} 
un alcaid o capità nomenat pel Mestre $i$ les seues rendes engrossaren els recursos de la Mesa Mestral.

Quant al carrec de Comanador Major, també el segle XV no el va veure consolidat d'una forma definitiva $i$ va anar itinerant entre diverses comandes, potser buscant en cadascun dels moments aquella que implicara uns ingressos més notables per al frare posseïdor de tan alta titulació en la jerarquia montesiana. Si en 1414 passà de la comanda de Peniscola a la de Culla, en 1470 el trobem com a titular de la comanda de Benicarlo i Vinaros, en 1475 de la de Xivert $i$ en 1482 de la de Les Coves de Vinromà. Respecte al Clauer, tot indica que vers finals del segle $X V$ va anar perdent competencies en favor de la Mesa Mestral; aixl, en 1475 el Clauer signava els documents titulant-se Comanador de Sueca, tot i que les rendes d'aquesta vila eren ja gestionades i administrades directament pels oficials delegats del Mestre de Montesa; el títol administratiu encara és emprat en 1506, quan el Clauer i comanador de Sueca, Silla i Montroi participà del Capitol general de Montesa per elegir nou Mestre ${ }^{46}$.

Fent un balanç ràpid dels segles medievals, podem afirmar de forma clara que fou caracteristic en l'organització interna de l'Orde de Montesa el predomini majoritari dels Mestres sobre la resta dels frares montesians. Després d'unes breus etapes inicials i ràpides de canvis en la seua estructura interna de poder, durant la decada del 1320, amb l'aparicio de la figura dels Comanadors, el punt d'inflexio va donar-se en el capitol del 1330; arran d'aquest el model de jerarquitzacio intern de l'Orde militar va decantar-se vers un model dual, Mestre versus Comanadors, tot i que la creacio d'un tercer ambit de destinació les rendes senyorials, el "Fons Comú", en bona mesura sota el control del mateix Mestre, palesa que sols assistim a una primera fase de creacio d'un poder relativament autonom dels Comanadors a les seues respectives comandes.

Cal tenir en compte que l'Orde de Montesa és un Orde Militar centrat estrictament en l'ambit del Pals Valencià durant l'època medieval i moderna, la qual cosa implica que, tot i ser durant els segles XIV i XV una entitat situada al cim de la jerarquia feudal valenciana -són els senyors amb més territori $i$ vassalls-, la capacitat d'expansio $i$ ampliació de les seues bases patrimonials fou limitada en comparacio amb d'altres Ordes militars peninsulars. A més a més, tot i que parlem de "l'Orde de Montesa", aquest

\footnotetext{
${ }^{46}$ ARV, ibidem, entre d'altres textos coetanis.
} 
no és un organisme únic ni homogeni: sota certes actuacions conjuntes de tots els frares mitjançant els Capitols, els Mestres foren els qui mantingueren constantment la direccio i veu pública de la institució. Conseqüencia d'aquestes limitacions és el que bona part de les mesures de reorganització interna varen anar dirigides vers l'enfortiment de les rendes $\mathrm{i}$ els ingressos de la Mesa Mestral, la qual cosa pot anar constatant-se al llarg del segle XIV amb un ampli ventall de rendes puntuals les quals són apropiades en benefici seu Paral.lelament, perd, podem parlar d'un reconeixement factic del poder autonom dels Comanadors a les seues comandes front de la jerarquia del Mestre: no són els seus delegats ni administradors, sinó que gaudissen de poder polític i poder fiscal en benefici propi, tot i que amb un traspàs parcial dels seus ingressos feudals en favor de l'esmentada Mesa Mestral.

A més a més, el pas al segle XV ens permet comprovar com la jerarquització dels poders interns a l'Orde de Montesa no féu sinó consolidar-se en favor dels Mestres, bàsicament per l'augment de la relació seua amb la Corona; casos com els de fra Romeu de Corbera en temps d'Alfons el Magnànim, o de fra Lluís Despuig en la segona meitat del segle XV, són bona prova d'aquesta evolució. Com tants altres membres de la noblesa de la Corona d'Arago, els Mestres de Montesa trobaren al llarg del segle XV, especialment a partir de la nova dinastia Trastàmara, una font de finançament i recuperacio d'ingressos fora dels seus estats patrimonials: salaris, donacions, recompenses i càrrecs per part de la Corona. A fi de comptes és el que va passar a tot Europa, on les monarquies feren créixer l'incipient aparell de l'Estat i la noblesa, greument afectada per la crisi baix-medieval, va apropar-se a la nova font de recursos que era el rei. Sota les seues branques, al seu caliu, trobarem sempre els Mestres de Montesa.

\section{RÉSUMÉ}

La plupart des travaux sur l'histoire de l'Ordre Militaire de Montesa ont été basés sur des oeuvres classiques ecrites à l'époque Moderne, et pour cette raison ont altribué des schémas a des formes d'organisation aux temps médiévaux sans aucun sens. L'objectif de ce travail est d'essayer de montrer quelle a été la distribution territoriale de la seigneurie de Montesa au Pays Valencien au moment de sa fondation, ainsi que son évolution pendant l'époque médiévale tout en prétant une attention particulière a la séparation des poivoirs at des compétences entre les frères membres de l'Ordre et le Maître, possesseur des droits de la Table "Maestral". On peut constater pendant les XIVème at XVŻme siècles, une hierarchisation a une concentration des pouvoirs entre les mains du Maître, qui lui ont permis d'agir 
très independemment comme un grand pouvoir ftodal, tandis que les commandeurs sont clairement restes au second rang, avec peu de réssources économiques.

\section{SUMMARY}

The majority of works on the history of the Military Order of Montesa are based on classic works referring to the Modem Ages and therefore they assign to the Middle Ages meaningless schema and organizational outlines. The purpose of this paper is to find out the territorial distribution of the Montess manors in the Kingdom of Valencia at the time of its foundation, and its changes through the Middle Ages, emphasizing the distribution of powers and competences between the Friars memberships of the Order and the Master, owner of the rights of the "Mesa Maestral". We know that during the XIV and XV Centuries there was a concentration of powers in the hands of the Master. With this authority, his great feudal power could become self-sufficient while the Friars were left with few economic resources. 